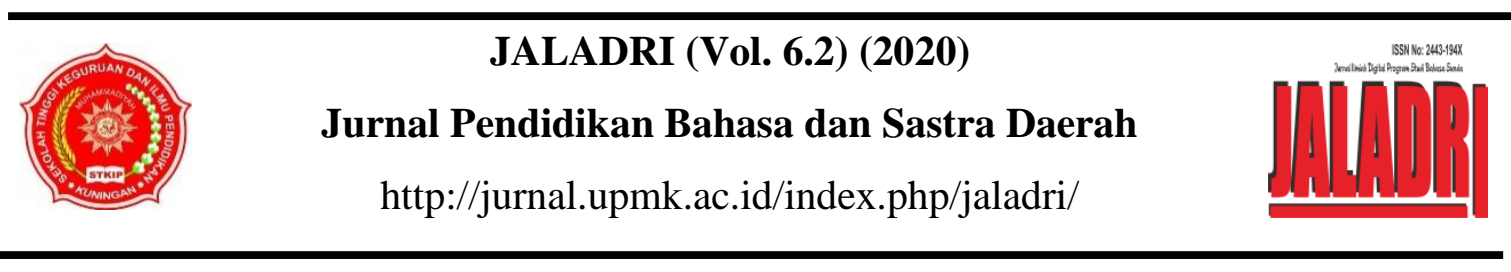

\title{
PENGARUH TEKNIK TALKING CHIPS UNTUK MENINGKATKAN KEMAMPUAN BERBICARA DALAM DISKUSI SISWA KELAS VIII SMP NEGERI 1 MALEBER
}

\section{Syamsur Ramdhan Firdaus}

email: ramdhan.firdaus@gmail.com

STKIP Muhammadiyah Kuningan

\begin{tabular}{l}
\hline Info Artikel \\
\hline Sejarah Artikel: \\
Diterima 10 Agustus 2020 \\
Disetujui 10 Oktober 2020 \\
Dipublikasikan 25 Oktober 2020
\end{tabular}

Kata Kunci:

Talking Chips, Kemampuan Berbicara, Diskusi.

\begin{abstract}
Abstrak
Penelitian ini bertujuan untuk mengetahui peningkatan kemampuan berbicara siswa setelah penerapan model cooperative learning teknik talking chip pada pembelajaran diskusi di kelas VIII SMP Negeri 1 Maleber. Permasalahan dalam penelitian ini dirumuskan dalam bentuk pertanyaan, yaitu: (1) bagaimana kemampuan berbicara siswa?, (2) bagaimana kemampuan berbicara siswa setelah menggunakan teknik talking chip?, dan (3) bagaimana implementasi teknik talking chip dalam proses pembelajaran?. Hipotesis dalam penelitian ini yaitu: "adanya pengaruh yang signifikan dari pemakaian teknik talking chip terhadap kemampuan berbicara siswa kelas VIII di SMP Negeri 1 Maleber". Metode penelitian yang dipakai dalam penelitian ini yaitu metode eksperimen. Populasi yang diteliti yaitu semua siswa kelas VIII di SMP Negeri 1 Maleber Taun Ajaran 2014-2015. Dalam penelitian ini quota sampling digunakan untuk mendapatkan sampel. Penelitian ini menggunakan dua sampel yaitu siswa kelas VIII B sebagai kelas eksperimen dan siswa kelas VIII F sebagai kelas kontrol, yang jumlahnya 60 siswa. Instrumen yang dipakai untuk mengumpulkan data yaitu: (1) Observasi dilakukan untuk mengetahui kemampuan berbicara siswa dalam pelajaran Bahasa Sunda di kelas VIII SMP Negeri 1 Maleber, (2) tes lisan agar dapat mengetahui kemampuan berbicara siswa sebelum (pretest) atau sesudah (posttest) menerapkan teknik talking chip. Tekhnik analisis data dalam penelitian kuantitatif menggunakan statistik. Hasil penelitian dan hitungan ststistik nilai tes ahir (posttets) menunjukan nilai $t_{\text {hitung }}=6,41$ menggunakan $\alpha=0,05 \mathrm{dan} \mathrm{dk}=58$ diperoleh $t_{\text {tabel }}=2,00$. jadi $t_{\text {hitung }}(6,41)>t_{\text {tabel }}(2,00)$. Artinya hipotésis Ha diterima, ada pengaruh yang signifikan dari pemakaian teknik talking chip terhadap peningkatan kemampuan berbicara dalam diskusi siswa kelas VIII dalam di SMP Negeri 1 Maleber. Jadi teknik talking chip terhadap peningkatan kemampuan berbicara dalam diskusi siswa kelas VIII di SMP Negeri 1 Maleber memiliki pengaruh yang positif untuk meningkatkan kemampuan siswa.
\end{abstract}


Key Words:

Talking Chips,

Speech,

Discussion.
This research target to determine the increase students' ability to speak after the implementation of cooperative learning model of talking chip on learning techniques in the classroom discussion VIII SMP Negeri 1 Maleber. The problems in this research will formulated with the questions, that is: (1) how the students speaking ability?, (2) how the students speaking ability after using the technique of talking chips?, and (3) how the technical implementation talking chip in the learning process?. The hypothesis in this research, that is: "the existence of a significant effect of the use of the technique of the speech talking chip class VIII SMP Negeri 1 Maleber". The research method used in this study is the experimental method. Population studied were all students of class VIII SMP Negeri 1 Maleber learning years 2014-2015. In this research used "quota sampling" to obtain samples. This research uses two samples that eighth grade students as an experimental class $B$ and class VIII $F$ as the control class. The amout of all student is 60. Instruments used to collect data: (1) Observation conducted to determine the ability of speaking students in learning Sundanese language in class VIII SMP Negeri 1 Maleber, (2) The Speaking test in order to determine their speaking ability before (pretest) or after (posttest) apply the technique talking chips. Data analysis techniques in "kuantitatif" research using statistics. The result of research and statistic calculation posttest show the assess $t_{\text {hitung }}=6.41$ using $\alpha=0.05$ and $d k=58$ retrieved $t_{\text {tabel }}=2.00$. so $t_{\text {hitung }}(6.41)>t_{\text {tabel }}(2.00)$. it means the hypothesis Ha was accepted, there is a significant effect of the use of techniques to increase the ability of talking chip speaking in class VIII SMP Negeri 1 Maleber. So talking chip technique in improving their speaking ability in class VIII SMP Negeri 1 Maleber have a positive influence to improve the ability of students. 


\section{PENDAHULUAN}

Belajar merupakan proses berubahnya tingkahlaku individu sebagai hasil pengalaman dari lingkungannya. Jadi, kebiasan belajar mempunyai pengaruh terhadap hasil belajar. Biasanya prosas pebelajaran yang baik yaitu ketika materi yang dibahas oleh guru dapat dimengerti oleh siswa. Guru sebagai fasilitator harus tahu masalah-masalah apa saja yang akan mengganggu proses pebelajaran. Selain itu, guru juga harus menguasai beberapa metode atau téknik paembelajaran agar dalam berlangsungnya proses pembelajaran mendapatkan hasil yang maksimal.

Berbicara termasuk dalam kemampuan berbasa yang bersipat produktif. Berbicara merupakan sarana yang digunakan untuk meyampaikan maksud atau informasi dari satu pihak ke pihak lain. Oleh sebab itu, berbicara harus disampaikan dengan baik dan benar agar maksud pembicaraan bisa diterima oleh orang lain dengan benar. Untuk memenuhi hal tersebut kemampuan berbicara sangat dibutuhkan.

Setiap siswa mempunyai karakteristik yang berbeda-beda. Berdasarkan hal tersebut, tidak semua siswa mempunyai kemampuan untuk melaksanakan proses pembelajaran dengan baik, sedangkan sebagian siswa mempunyai masalah atau kendala dalam proses pembelajaran. Salah satunya adalah masalah dalam kemampuan berbicara, ketika berbicara siswa mempunyai kendala dalam mengungkapkan ide atau gagasannya. Untuk mengetahui kemampuan kemampuan berbicara siswa, bisa digunakan beberapa cara, salah satunya melalui dikusi kelas.

Dalam Kurikulum Tingkat Satuan Pendidikan (KTSP) bahasa Sunda, diskusi kelompok menjadi salah satu kompetensi dasar dari kemampuan berbicara. Tujuan dari diskusi yaitu agar siswa bisa berperan aktif dalam pembelajaran serta belajar mengeluarkan pendapatnya, dalam hal ini berkaitan dengan salah satu aspek kemampuan berbahasa, yaitu berbicara. Selain itu Muhamad Surya (2003:59) menyebutkan bahwa diskusi kelas termasuk ke dalam model Concurrent Learning (pembelajaran secara bersama-sama) sebab ada partisipasi dari siswa, dilakukan dalam forum terbuka, serta suasana damokratis.

Kemampuan berbicara siswa dalam pembelajaran kadang-kadang tidak dilatih atau dipraktekan, sebab pembelajaran lebih ditekankan terhadap penguasaan matéri. Padahal kemampuan berbicara bukan hanya dari menguasai materi, tapi memerlukan latihan dan praktek dalam proses pembelajaran. Selain itu, proses pembelajaran masih menggunakan metode konvensional yaitu metode ceramah sehingga semua informasi berpusat di guru yang akhirnya siswa tidak diberi kesempatan untuk mengeluarkan apa yang ada dalam pikirannya serta menciptakan suasana yang pasif dalam proses pembelajaran.

Hal tersebut yang mengakibatkan kurangnya kemempuan berbicara siswa. Metode, teknik dan model pembelajaran yang varéatif akan meningkatkan proses pembelajran yang pasif menjadi aktif. Dalam pembelajaran berbicara, perlu ada model pembelajran yang bisa merangsang siswa untuk berbicara Tapi, kebanyakan hanya beberapa siswa yang mendominasi dalam berbicara sedangkan sebagian lagi hanya bisa mendengarkan. Kasus seperti ini merupakan hal yang wajar, sebab satiap siswa mempunyai karakteristiknay masing-masing. Cara untuk menangani hat tersebut, peneliti akan menggunakan model pembelajaran Cooperative Learning teknik Talking Chips. Anita Lie (2008:63) menyebutkan bahwa dalam Kancing Gemerincing, masingmasing anggota kelompok mendapatkan kesempatan untuk memberikan kontribusi mereka dan mendengarkan pandangan dan pemikiran anggota yang lain. Jadi, teknik Talking Chips dianggap efektif sebab setiap siswa diberi kesempetan untuk berbicara.

Berdasarkan pembahasan di atas, peneliti tertarik untuk mengadakan penelitian yang berjudul "Pangaruh Téknik Talking Chips Kana Ngaronjatkeun Kamampuh Nyarita Dina Sawala Siswa Kelas VIII SMP Negeri 1 Maleber". Dengan adanya penelitian ini, diharapkan kemampuan berbicara dalam diskusi siswa kelas VIII SMP Negeri 1 Maleber akan meningkat.

Berdasarkan latar belakang di atas, masalah dalam penelitian ini dirumuskan dalam bentuk pertanyaan, yaitu:

1. Bagaimana implementasi proses pembelajaran berbicara dalam diskusi di Kelas VIII SMP Negeri 1 Maleber?

2. Bagaimana kemampuan berbicara siswa dalam diskusi siswa SMP Negeri 1 Maleber?

3. Bagaimana pengaruh teknik talking chips terhadap kemampuan berbicara dalam diskusi siswa SMP Negeri 1 Maleber? 
Berdasarkan rumusan masalah di atas, penelitian ini mempunyai tujuan yang ingin dicapai, yaitu:

1. Untuk mendeskrisikan implementasi teknik Talking Chips dalam proses pembelajaran berbicara dalam diskusi di Kelas VIII SMP Negeri 1 Maleber.

2. Untuk mengetahui kemampuan berbicara siswa dalam diskusi sebelum model pembelajaran kooperatif teknik talking chips diterapkan.

3. Untuk mengetahui peningkatan kemampuan berbicara siswa dalam diskusi setelah model pembelajaran kooperatif teknik talking chips diterapkan.

\section{METODE PENELITIAN}

\section{a. Jenis dan Desain Penelitian}

Penelitian adalah kegaitan mencari, mencatat, merumuskan, menganalisis serta menyusun laporan (Cholid Narbuko dan Abu Ahmad, 2012:1). Agar tercapai tujuan penelitian juga dapat menjawab masalahmasalah yang sedang diteliti, maka diperlukan medote penelitan. Metode penelitian yang dipakai dalam penelitian ini yaitu metode eksperimen. Metode eksperimen dapat diartikan sebagai metode penelitian yang digunakan untuk mencari pengaruh perlakuan tertentu terhadap yang lain dalam kondisi yang terkendalikan (Sugiyono, 2015:109).

Langkah-langkah metode eksperimen, yaitu:

a. Mengadakan pretest untuk mengetahui dan mengukur sejauh mana kemampuan berbicara dalam diskusi siswa.

b. Mengadakan kegiatan pembelajaran di kelas eksperimen yang menggunakan model pembelajaran kooperatif teknik talking chips dan di kelas kontrol yang tidak menggunakan model pembelajaran kooperatif teknik talking chips.

c. Mengadakan posttest, di kelas eksperimen dan di kelas kontrol menggunakan tes yang sama, untuk mengetahui sejauh mana kemampuan berbicara siswa dalam diskusi sesudah pembelajaran berlangsung.

Desain merupakan kerangka, pola yang menggambarkan alur dan arah penelitian. Desain yang digunakan dalam penelitian ini adalah desain kelompok kontrol pretestposttest Control Group Design. Berdasarkan desain tersebut, maka diperlukan dua kelompok siswa yang akan dibandingkan hasilnya, yaitu kelompok I sebagai kelompok kelas eksperimen yang menggunakan model pembelajaran kooperatif teknik talking chips, dan kelompok II selaku kelas kontrol yang tidak menggunakan model pembelajaran kooperatif teknik talking chips.

b. Teknik Menentukan Populasi dan Sampel

1) Populasi

Populasi dalam penelitian ini yaitu semua siswa kelas VIII di SMP Negeri 1 Maleber Kecamatan Maleber Kabupaten Kuningan Taun Ajaran 20142015.

2) Sampel

Dalam penelitian ini, Quota Sampling dipakai untuk menentukan sampel. Dalam penelitian ini menggunakan dua sampel yaitu siswa kelas VIII B sebagai kelas eksperimen dan siswa kelas VIII F sebagai kelas kontrol, yang jumlahnya 60 siswa.

Data Sampel Siswa

\begin{tabular}{|c|c|c|c|}
\hline Kelas & L & P & $\begin{array}{c}\text { Jumlah } \\
\text { Siswa }\end{array}$ \\
\hline VIII B & 18 & 14 & 32 \\
\hline VIII F & 17 & 11 & 28 \\
\hline Jumlah & 35 & 25 & 60 \\
\hline
\end{tabular}

\section{c. Teknik Mengumpulkan Data}

Instrument yang dipakai untuk mengumpulkan data yaitu:
1) Observasi
Observasi ini dilakukan untuk mengetahui hasil belajar bahasa
Sunda khususnya berbicara dalam diskusi di kelas VIII SMP Negeri 1 Maleber.
2) Tes 
Tes sebagai bahan evaluasi untuk mengetahui pengaruh pembelajaran kooperatif teknik talking chips terhadap kemampuan berbicara dalam diskusi siswa kelas VIII SMP Negeri 1 Maleber. Mengenai bentuk tes yang dipakai yaitu tes lisan, tes kemampuan berbicara dalam diskusi.

3) Dokumentasi

Hasil penelitian dari observasi atau wawancara lebih bisa dipercaya andaikan didukung oleh dokumen/dokumentasi yang kredibel.

\section{d. Teknik Analisis}

Kegiatan analisis data yaitu membahas data setiap variabel yang diteliti, menghitung nilai untuk menjawab rumusan masalah, dan mengadakan perbandingan untuk menguji hipotesis yang diajukan dalam penelitian ini. Tekhnik analisis data dalam penelitian kuantitatif menggunakan statistik. Tahap mengolah data dilakukan dengan cara mengumpulkan data menggunakan pretest dan posttest. Sesudah data terkumpul lalu data diolah melalui langkah-langkah sebagai berikut:

1) Tes Normalitas Distribusi

Tes normalitas distribusi mempunyai tujuan untuk mengetahui kenormalan dari sebaran data. Adapun langah uji normalitas yaitu:

a) Mencari rata-rata

Rumus mencari rata-rata (Sudjana, 2005:87).

$$
\bar{x}=\frac{\sum x}{n}
$$

Keterangan:

$\bar{x} \quad=$ Rata-rata

$\sum x=$ Jumlah $\mathrm{x}$

$n \quad$ Jumlah sampel

b) Mencari standar deviasi

Rumus mencari nilai standar deviasi (Sudjana, 2005:89).

$$
S d=\sqrt{\frac{\sum(x-\bar{x})^{2}}{n-1}}
$$

c) Menghitung nilai $\chi^{2}$
Rumus yang digunakan yaitu chi kuadrat (Arikunto, 2006:57). Rumus mencari nilai $\chi^{2}$ seperti di bawah:

$\chi^{2}=\sum_{\mathrm{i}=1}^{\mathrm{k}} \frac{(\mathrm{Oi}-\mathrm{Ei})}{\mathrm{Ei}}$

Keterangan:

$\mathrm{K}=$ Jumlah korelasi interval

$\mathrm{Oi}=$ Frekuensi hasil

pengamatan

$\mathrm{Ei}=$ Frekuensi yang

diharapkan

$\chi^{2}=$ Chi kuadrat

2) Uji Homogenitas

Uji homogenitas mempunyai tujuan untuk menentukan rumus uji hipotesis yang akan digunakan (Somantri, 2006:180). Rumus yang digunakan seperti di bawah ini.

$F=\frac{\text { varians terbesar }}{\text { varians terkecil }}$

Selanjutnya, $F$ hitung disamakan dengan $\mathrm{F}$ tabel, menggunakan $\alpha=$ $5 \%, \mathrm{db}=\mathrm{k}-1$. Seandainya $\mathrm{F}$ hitung $<\mathrm{F}$ tabel berarti data tersebut homogen.

3) Uji hipotesis

a) Uji t

Apabila ke dua data normal dan bervariansi homogen, dilanjutkan penghitungan uji t.

$\begin{array}{lr}\text { a) } & \text { standar } \\ \text { deviasi } & \text { gabungan }\end{array}$ menggunakan rumus:

$$
d s g=\sqrt{\frac{(n 1-1) v 1+(n 2-1) v 2}{n 1+n 2-2}}
$$

b) Mencari nilai $t$ menggunakan rumus:

$$
t=\frac{\bar{X} 1-\bar{x} 2}{d s g \sqrt{\frac{1}{n 1}+\frac{1}{n 2}}}
$$

Keterangan :

$\mathrm{dsg}=$ deviasi

standar gabungan

$\mathrm{X}_{1} \quad=$ rata-rata kelas terbesar 


$$
\begin{aligned}
& \mathrm{X}_{2} \quad=\text { rata-rata kelas } \\
& \text { terkecil } \\
& \text { c) Menentukan } \quad \mathrm{db} \\
& \text { menggunakan rumus } \\
& \mathrm{db}=\mathrm{n} 1+\mathrm{n} 2-2 \\
& \text { d) Menentukan nilai } t \\
& \text { tabel } \\
& \text { Kriteria pengujian } \\
& \text { hipotesis diterima } \\
& \text { apabila: } \\
& \mathrm{t} \text { hitung ada di luar } \\
& \text { interval } 1-\mathrm{t}-1 / 2 \alpha<\mathrm{t} \\
& <\mathrm{t} 1-1 / 2 \alpha \\
& t^{\prime}=\frac{\overline{X_{1}}-\overline{X_{2}}}{d s g \sqrt{\frac{V_{1}+V_{2}}{n_{1}+n_{2}}}} \\
& \mathrm{~V}_{1}=\text { Variansi data } \\
& \text { kelompok } 1 \\
& \mathrm{~V}_{2}=\text { Variansi data } \\
& \text { kelompok } 2 \\
& \mathrm{n}_{1}=\text { Jumlah kelompok } 1 \\
& \mathrm{n}_{2}=\text { Jumlah kelompok } 2
\end{aligned}
$$

\section{HASIL DAN PEMBAHASAN}

\section{1) Implementasi Proses Pembelajaran Berbicara dalam Diskusi di Kelas Kontrol}

Kelas kontrol dalam penelitian ini adalah kelas VIII $F$ yang berjumlah 28 siswa. Kelas kontrol merupakan kelas yang tidak mendapatkan perlakuan penerapan teknik talking chips atau menggunakan pembelajaran konvensional. Dalam proses pembelajaran guru membuka pembelajaran dengan berdo'a dan mengabsen siswa, setelah itu guru mengapresisasi dan memotivasi siswa untuk belajar. Selanjutnya guru menjelaskan bahwa akan diadakan tes akhir (posttest) melalui diskusi.

Guru membagi siswa ke dalam enam kelompok, dengan cara siswa berhitung dari satu sampai enam. Setelah berhitung siswa bergabung dengan kelompoknya berdasarkan nomor yang dimiliki, jadi siswa yang mendapat no satu berkelompok dengan siswa yang mendapat nomor satu juga. Begitu juga yang lainnya. Dalam pembagian kelompok masih ada saja permasalahan, yaitu siswa harus merubah posisi duduk berdasarkan kelompoknya masingmasing, hal tersebut membuat keadaan kelas menjadi ribut.

Sebelum diskusi dimulai guru menjelaskan masalah yang akan didiskusikan oleh kelompok, yaitu mengenai pelestarian bahasa Sunda yang berbentuk pertanyaan "Bagaimana cara melestarikan bahasa Sunda?" Agar anak-anak dalam berbicara lebih dominan menggunakan bahasa Sunda daripada bahasa Indonesia. Ketika kegiatan diskusi berlangsung, guru mengarahkan dan menilai kegiatan diskusi siswa. Dalam diskusi hanya sebagian siswa yang ikut aktif dalam diskusi sedangkan siswa yang lainnya tidak serius dan hanya bercanda walaupun sudah diarahkan dan ditegor oleh guru.

Setelah diskusi selesai, perwakilan kelompok membacakan hasil diskusi kelompoknya di depan kelas. Setelah semua kelompok membacakan hasil diskusinya guru menyimpulkan cara yang efektif dalam melestarikan bahasa Sunda. Pembelajaran di tutup dengan berdo'a bersama-sama.

Jadi di kelas kontrol pembelajaran berlangsung kurang tertib, sebab saat diskusi berlangsung siswa hanya bercanda dan tidak serius serta tidak memperhatikan pendapat siswa lainnya. Berdasarkan hal tersebut bisa dilihat bahwa pembelajaran konvensional masih kurang dalam meningkatkan kemampuan berbicara siswa dalam diskusi.

\section{2) Implementasi Proses Pembelajaran Berbicara dalam Diskusi di Kelas Eksperimen}


Kelas eksperimen dalam penelitian ini adalah kelas VIII B yang berjumlah 32 siswa. Kelas eksperimen merupakan kelas yang mendapat perlakuan penerapan teknik talking chips. Dalam proses pembelajaran guru membuka pembelajaran dengan berdo'a dan mengabsen siswa, setelah itu guru mengapersepsi dan memotivasi siswa untuk diajar. Selanjutnya guru menjelaskan bahwa akan diadakan tes akhir (posttest) melalui diskusi dengan menggunakan teknik talking chips.

Guru membagi siswa ke dalam enam kelompok, dengan cara siswa berhitung dari satu sampai enam. Setelah berhitung siswa bergabung dengan kelompoknya berdasarkan nomor yang dimiliki, jadi siswa yang mendapat no satu berkelompok dengan siswa yang mendapat nomor satu juga, begitu juga yang lainnya. Dalam pembagian kelompok masih ada saja permasalahan, yaitu siswa harus merubah posisi duduk berdasarkan kelompoknya masingmasing, hal tersebut membuat keadaan kelas menjadi ribut.

Sebelum diskusi dimulai guru menjelaskan masalah yang akan didiskusikan dan langkah-langkah pembelajaran kooperatif teknik talking chips. Masalah yang akan didiskusikan, yaitu mengenai pelestarian bahasa Sunda yang berbentuk pertanyaan "Bagaimana cara melestarikan bahasa Sunda?" Agar anak-anak dalam berbicara lebih dominan menggunakan bahasa Sunda daripada bahasa Indonesia. Selanjutnya guru menjelaskan mengenai pembelajaran kooperatif teknik talking chips. Pembelajaran kooperatif teknik talking chips merupakan model pebelajaran yang baru bagi siswa kelas VIII SMP Negeri 1 Malébér. Oleh sebab itu, guru harus lebih detail menjelaskan langkah-langkah pembelajaran kooperatif teknik talking chips.

Langkah-langkah pembelajaran kooperatif teknik talking chips, yaitu: 1) guru membagi siswa ke dalam enam kelompok, 2) setiap anggota kelompok mempunyai dua sendok es krim, 3) sendok es krim tersebut disimpan di depan setiap siswa, 4) setiap siswa yang mengeluarkan ide atau gagasannya, siswa tersebut harus menyimpan salah satu sendok es krim di tengah-tengah meja kelompokna, 5) jika sendok es krim salah satu siswa sudah habis, siswa tersebut tidak boleh berbicara sampai anggota lainnya menghabiskan seéndok es krimnya, dan 6) jika semua sendok es krim sudah habis, tapi masih ada yang ingin mengeluarkan pendapatnya, kelompok bisa membagikan kembali sendok es krim kepada setiap anggota serta menjalankan kembali prosedurnya.

Ketika kegiatan diskusi berlangsung, guru mengarahkan dan menilai kegiatan diskusi siswa. Guru juga memotivasi siswa dengan cara memberi hadiah yang berupa permen kepada kelompok yang semua anggotanya bisa mengeluarkan pendapatnya. Selain itu, guru juga memuji siswa yang sudah mengeluarkan pendapatnya dengan cara menyebut bagus, leres pisan, dsb. Dalam diskusi siswa terlihat antusias dalam belajar. Ada empat kelompok yang lancar dalam mengeluarkan pendapatnya, terlihat dari kegiatan siswa yang lebih aktif dalam berdiskusi, lebih gampang mengeluarkan pendapatnya, dan kompak dalam berdiskusi. Sedangkan dua kelompok masih mempunyai masalah dalam mengeluarkan pendapatnya, hal tersebut menghambat siswa lain yang ingin mengeluarkan pendapatnya.

Setelah diskusi selesai, perwakilan kelompok membacakan hasil diskusi kelompoknya di depan kelas. Setelah semua kelompok membacakan hasil diskusinya guru menyimpulkan cara yang efektif dalam melestarikan bahasa Sunda. Pembelajaran di tutup dengan berdo'a bersama-sama.

Jadi di kelas eksperimen pembelajaran berlangsung tartib, sabab dalam proses pembelajaran 
menggunakan teknik talking chips, siswa tertarik untuk belajar. Hal ini dapat dilihat dari proses pembelajaran, seperti dalam kerja kelompok siswa lebih aktif dalam mengerjakan tugasnya, siswa lebih antusias dalam belajar, lebih gampang mengeluarkan pendapatnya, serta kompak dalam diskusi dan menyimpulkan hasil diskusi. Oleh sebab itu, pembelajaran yang menggunakan model pembelajaran kooperatif teknik talking chips menunjukan bahwa pembelajaran berpusat pada siswa.

\section{a. Pembahasan Hasil Penelitian}

1) Hasil Tés Awal (pre-test)

Tes awal (pretest) ditujukan kepada ke dua kelas subjek penelitian yaitu kelas eksperimen dan kelas kontrol sebelum pembelajaran dilakukan. Berdasarkan pengolahan data hasil tes awal (pretest) kelas eksperimen dan kelas kontrol, mendapat data seperti di bawah.

Hasil Data Tes Awal (Pretest)

\begin{tabular}{|c|c|c|c|}
\hline \multirow{2}{*}{$\begin{array}{l}\mathbf{N} \\
\mathbf{0}\end{array}$} & \multirow{2}{*}{$\begin{array}{c}\text { Data } \\
\text { Penelitian }\end{array}$} & \multicolumn{2}{|c|}{ Kelas } \\
\hline & & $\begin{array}{c}\text { Ékspérimé } \\
\text { n }\end{array}$ & $\begin{array}{c}\text { Kontro } \\
1\end{array}$ \\
\hline 1 & $\begin{array}{l}\text { Jumlah } \\
\text { Siswa }\end{array}$ & 32 & 28 \\
\hline 2 & $\begin{array}{l}\text { Niléy } \\
\text { panggedéna }\end{array}$ & 67 & 67 \\
\hline 3 & $\begin{array}{l}\text { Niléy } \\
\text { pangleutikn } \\
\text { a }\end{array}$ & 33 & 33 \\
\hline 4 & Niléy Total & 1583 & 1292 \\
\hline 5 & $\begin{array}{l}\text { Rata-rata } \\
\text { Niléy }\end{array}$ & 49 & 46 \\
\hline 6 & $\begin{array}{l}\text { Standar } \\
\text { Deviasi }\end{array}$ & 13,5 & 12,7 \\
\hline
\end{tabular}

Tabel di atas menunjukan bahwa hasil dari tes awal (pretes) kelas eksperimen dan kelas kontrol mempunyai nilai total yang tidak jauh beda. Dalam kelas eksperimen yang berjumlah 32 siswa mendapat nilai total 1583 , rata-rata 49 , nilai tertinggi 67 , nilai terendah 33, dan standar deviasi 13,5. Sedangkan kelas kontrol yang berjumlah 28 siswa mendapat nilai total 1292 , ratarata 42 , nilai tertinggi 67 , nilai terendah 33, dan standar deviasi 12,7 .

2) Hasil Tes Akhir (Post-test)

Sesudah pembelajaran yang berbeda antara kelas eksperimen dan kelas kontrol berlangsung. Berdasarkan pengolahan data hasil tes ahir (posttest) kelas eksperimen dan kelas kontrol, mendapat data seperti di bawah ini.

Hasil Data Tes Akhir (Post-test)

\begin{tabular}{|c|c|c|c|}
\hline \multirow{2}{*}{$\begin{array}{l}\mathbf{N} \\
\mathbf{0}\end{array}$} & \multirow{2}{*}{$\begin{array}{c}\text { Data } \\
\text { Peneliti } \\
\text { an }\end{array}$} & \multicolumn{2}{|c|}{ Kelas } \\
\hline & & $\begin{array}{c}\text { Ékspéri } \\
\text { mén }\end{array}$ & $\begin{array}{c}\text { Kont } \\
\text { rol }\end{array}$ \\
\hline 1 & $\begin{array}{l}\text { Jumlah } \\
\text { Siswa }\end{array}$ & 32 & 28 \\
\hline 2 & $\begin{array}{l}\text { Niléy } \\
\text { pangged } \\
\text { éna }\end{array}$ & 100 & 83 \\
\hline 3 & $\begin{array}{l}\text { Niléy } \\
\text { pangleut } \\
\text { ikna }\end{array}$ & 58 & 33 \\
\hline 4 & $\begin{array}{l}\text { Niléy } \\
\text { Total }\end{array}$ & 2533 & 1525 \\
\hline 5 & $\begin{array}{l}\text { Rata-rata } \\
\text { Skor }\end{array}$ & 79 & 54 \\
\hline 6 & $\begin{array}{l}\text { Standar } \\
\text { Deviasi }\end{array}$ & 11,0 & 18,4 \\
\hline
\end{tabular}

Tabel di atas menunjukan bahwa hasil tes akhir atau post-test kelas eksperimen dan kelas kontrol mempunyai nilai total yang jauh berbeda. Dalam kelas eksperimen yang berjumlah 32 siswa mendapat nilai total 2533 , rata-rata 79 , nilai tertinggi 100 , nilai terendah 58, dan standar deviasi 11,0. Sedangkan kelas kontrol yang berjumlah 28 siswa mendapat nilai total 1525 , ratarata 54 , nilai tertinggi 83 , nilai terendah 33, dan standar deviasi 18,4 .

3) Uji Normalitas Data

a) Uji Normalitas Data Tes Awal (pretest) 
Hasil Uji Normalitas Data Tés

Awal (pre-test)

\begin{tabular}{|c|c|c|}
\hline $\begin{array}{c}\text { Statisti } \\
\mathbf{k}\end{array}$ & $\begin{array}{c}\text { Kelas } \\
\text { Ékspér } \\
\text { imén }\end{array}$ & $\begin{array}{c}\text { Kelas } \\
\text { Kontro } \\
\mathbf{1}\end{array}$ \\
\hline$x_{\text {hitung }}^{2}$ & 0,00 & 0,00 \\
\hline$x_{\text {tabel }}^{2}$ & 7,81 & 7,81 \\
\hline
\end{tabular}

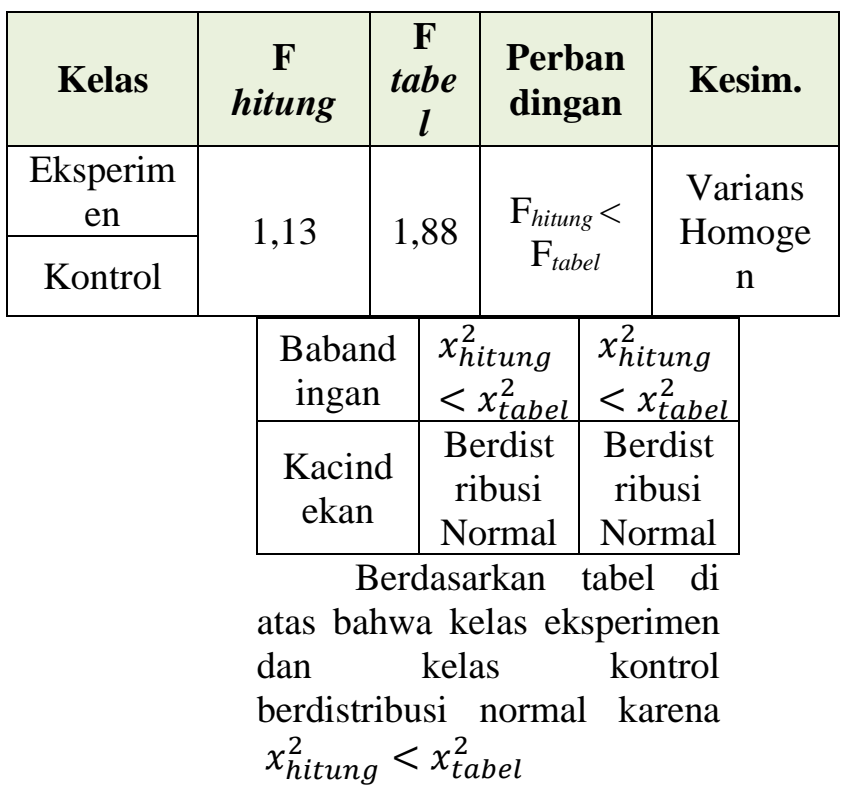

b) Uji Normalitas Data Tes

Akhir (posttest)

Hasil Uji Normalitas Data Tés

\begin{tabular}{|c|c|c|}
\hline \multicolumn{1}{|c|}{ Ahir (post-test) } \\
$\begin{array}{c}\text { Statisti } \\
\mathbf{k}\end{array}$ & $\begin{array}{c}\text { Kelas } \\
\text { Ékspér } \\
\text { imén }\end{array}$ & $\begin{array}{c}\text { Kelas } \\
\text { Kontro } \\
\mathbf{l}\end{array}$ \\
\hline$x_{\text {hitung }}^{2}$ & 0,00 & 0,00 \\
\hline$x_{\text {tabel }}^{2}$ & 7,81 & 7,81 \\
\hline $\begin{array}{c}\text { Baband } \\
\text { ingan }\end{array}$ & $\begin{array}{c}x_{\text {hitung }}^{2} \\
<x_{\text {tabel }}^{2}\end{array}$ & $\begin{array}{c}x_{\text {hitung }}^{2} \\
<x_{\text {tabel }}^{2}\end{array}$ \\
\hline $\begin{array}{c}\text { Kacind } \\
\text { ekan }\end{array}$ & $\begin{array}{c}\text { Berdist } \\
\text { ribusi } \\
\text { Normal }\end{array}$ & $\begin{array}{c}\text { Berdist } \\
\text { ribusi } \\
\text { Normal }\end{array}$ \\
\hline
\end{tabular}

Berdasarkan tabel di

atas bahwa kelas eksperimen dan kelas kontrol berdistribusi normal karena $x_{\text {hitung }}^{2}<x_{\text {tabel }}^{2}$.

4) Uji Homogenitas Data

Berdasarkan kepada hasil pengujian uji normalitas, apabila menunjukan ke dua kelas berdistribusi normal, selanjutnya dilakukan pengujian homogenitas. Hasil uji homogenitas dilakukan $\mathrm{ku}$ ngagunakeun uji $\mathrm{F}$. adapun kriteria uji homogenitas data seperti di bawah:

$F_{\text {hitung }}<F$ tabel, jadi ke dua kelompok disebut homogen

$F_{\text {hitung }}>F_{\text {tabel }}$, jadi ke dua kelompok disebut tidak homogen

$$
\text { a) Uji Homogenitas }
$$

Data Tes Awal (pretest)

Adapun hasil uji homogenitas tes awal (pretest) ke dua kelompok dijelaskan dalam tabel di bawah.

Hasil Uji Homogenitas (Uji

F) Data Tes Awal (pretest)

b) Uji HomogenitasData Tes Akhir (posttest)

Adapun hasil uji homogenitas tes ahir (posttest) ke dua kelompok dijelaskan dalam tabel di bawah.

Hasil Uji Homogenitas (Uji

F) Data Tes Akhir (posttest)

\begin{tabular}{|c|c|c|c|c|}
\hline Kelas & F hitung & $\begin{array}{c}\text { F } \\
\text { tabel }\end{array}$ & $\begin{array}{c}\text { Perban } \\
\text { dingan }\end{array}$ & $\begin{array}{c}\text { Kesi } \\
\mathbf{m} .\end{array}$ \\
\cline { 1 - 1 } $\begin{array}{c}\text { Eksperime } \\
\mathrm{n}\end{array}$ & 0,36 & 1,88 & $\begin{array}{c}\mathrm{F}_{\text {hitung }}< \\
\mathrm{F}_{\text {tabel }}\end{array}$ & $\begin{array}{c}\text { Varia } \\
\mathrm{ns} \\
\text { Homo } \\
\text { gen }\end{array}$ \\
\cline { 1 - 1 } Kontrol & & & &
\end{tabular}

5) Uji Hipotesis

Sebab kedua data tersebut berdistribusi normal dan homogen, selanjutnya pengujian hipotesis penelitian menggunakan uji t. Adapun hasil uji hipotesis tés akhir (post-test) dijelaskan pada tabel di bawah ini.

Hasil Uji hipotésis Tés Akhir (post-test)

\begin{tabular}{|c|c|c|c|c|c|}
\hline $\begin{array}{c}\text { Kel } \\
\text { as }\end{array}$ & $\begin{array}{c}\text { Rata- } \\
\text { rata }\end{array}$ & $\begin{array}{c}\mathbf{t} \\
\text { hitung }\end{array}$ & $\mathbf{t}_{\text {tabel }}$ & $\mathbf{d b}$ & $\begin{array}{c}\text { Kateran } \\
\text { gan }\end{array}$ \\
\hline $\begin{array}{c}\text { Éks } \\
\text { péri } \\
\text { mén }\end{array}$ & 79 & 6,41 & 2,00 & 58 & $\begin{array}{c}\text { Terima } \\
\text { Ha }\end{array}$ \\
\hline $\begin{array}{c}\text { Kon } \\
\text { trol }\end{array}$ & 54 & & & \\
\hline
\end{tabular}


Berdasarkan hasil hitungan diperoleh nilai $t_{\text {hitung }}=6,41$ menggunakan $\alpha=0,05$ dan $\mathrm{dk}=58$, didapat $t_{\text {tabel }}=2,00$. Jadi $t_{\text {hitung }}>$ $t_{\text {tabel }}$. Hal ini menunjukkan bahwa hasil tes akhir (post-test) siswa kelas eksperimen berbeda dengan siswa kelas kontrol. Artinay hipotesis Ha diterima, yaitu ada pengaruh teknik talking chips terhadap peningkatan kemampuan berbicara dalam diskusi siswa kelas VIII SMP Negeri 1 Maleber.

\section{KESIMPULAN}

Berdasarkan hasil penelitian yang dilakukan oleh peneliti mengenai pembelajaran kooperatif teknik talking chips terhadap peningkatan kemampuan berbicara dalam diskusi siswa kelas VIII SMP Negeri 1 Maleber. Pemakaian teknik talking chips terhadap peningkatan kemampuan berbicara dalam diskusi kelas VIII di SMP Negeri 1 Maleber, terlihat ada pengaruh yang signifikan. Dalam proses pembelajaran menggunakan téknik talking chips, siswa tertarik untuk belajar. Oleh sebab itu, pembelajaran yang menggunakan teknik talking chips mengajak siswa untuk belajar sambal bermain menggunakan chips (benda). Hal ini dapat dilihat dari proses pembelajaran, seperti dalam kerja kelompok siswa lebih aktif dalam mengerjakan tugasnya, siswa lebih antusias dalam belajar, lebih gampang dalam mengeluarkan pendapatnya, serta kompak dalam diskusi dan dalam menyimpulkan hasil diskusi. Intinya pembelajaran kooperatif teknik talking chips terpusat pada siswa.

Kemampuan berbicara dalam diskusi siswa kelas VIII SMP Negeri 1 Maleber sebelum menggunakan model pembelajaran kooperatif teknik talking chips atau dari hasil tes awal (pretest) hasilnya masih rendah dan tidak jauh berbeda, terlihat dari nilai terendah di kelas eksperimen yaitu 33 dan nilai tertinggi yaitu 67. Rata-rata nilai tes awal (pretest) kemampuan berbicara kelas eksperimen yaitu 49. Begitu juga nilai hasil tes awal (pretest) terendah di kelas kontrol yaitu 33 dan nilai tertinggi 67. Rata-rata nilai tes awal (pretest) kelas kontrol yaitu 46.

Kemampuan berbicara siswa setelah dilakukan tindakan atau pembelajaran di kelas eksperimen yang menggunakan model pembelajaran kooperatif teknik talking chips hasilnya lebih bagus. Hal ini bisa dilihat dari jumlah rata-rata nilai hasil tes akhir (posttest) yaitu 79. Nilai terendah 58 dan nilai tertinggi 100. Sedangkan kemampuan berbicara kelas kontrol yang tidak menggunakan teknik talking chips setelah pembelajaran atau tes akhir (posttest) hasilnya masih rendah. Hal ini dapat dilihat dari jumlah rata-rata nilai hasil tés akhir (posttest) yaitu 54. Nilai tereendah 33 dan nilai tertinggi 83.

\section{REFERENSI}

Arikunto, Suharsimi. 2010. Penelitian Tindakan Kelas. Jakarta: PT. Bumi Aksara.

Arikunto, Suharsimi. 2015. Prosedur Penelitian. Bandung: Alfabeta.

Danadibrata, R.A. 2006. Kamus Basa Sunda. Bandung: Kiblat.

Dinas Pendidikan Jawa Barat. 2014. Pamekar Diajar Basa Sunda Pikeun Guru SMP/MTs Kelas VIII. Bandung: DISDIK.

Huda, Miftahul. 2015. Cooperative Learning. Yogyakarta: Pustaka Belajar.

Lie, Anita. 2008. Cooperative Learning. Jakarta: Grasindo.

Rusman. 2012. Model-Model Pembelajaran. Jakarta: PT. Raja Grafindo Persada.

Sagala, Syaiful. 2013. Konsep dan Makna Pembelajaran. Bandung: Alfabeta.

Sugiyono. 2014. Metode Penelitian Kombinasi (Mixed Methods). Bandung: Alfabeta.

Sugiyono. 2013. Metode Penelitian Kuantitatif Kualitatif dan $R \& D$. Bandung: Alfabeta

Sugiyono. 2013. Statistika Untuk Penelitian. Bandung: Alfabeta.

Sukardi. 2014. Metodologi Penelitian Pendidikan. Jakarta: Bumi Aksara.

Surya, Muhammad. 2003. Psikologi Pembelajaran dan Pengajaran. Bandung: Yayasan Bhakti Winaya. 
Tarigan, Henry Guntur. 2013. Berbicara Sebagai

Suatu Keterampilan Berbahasa.

Bandung: Angkasa. 